\title{
An AAC tablet application for children with language impairment
}

\author{
Noura Al Ghurair***, Ghada Alnaqi* and Iyad Abu Doush** \\ *Kuwait Institute for Scientific Research \\ **American University of Kuwait \\ *Corresponding Author: nghurair@kisr.edu.kw
}

Submitted: 08/12/2019

Revised: $08 / 11 / 2020$

Accepted: $14 / 11 / 2020$

\begin{abstract}
People with communication impairment need an alternative communication channel to complete daily activities. Augmentative and alternative communication (AAC) systems can help provide a communication medium to support such users. The involvement of speech and language pathologists (SLPs) who work in rehabilitation centers can help develop better solutions. This paper presents the development of an AAC tablet application that uses pictures on the screen and voice feedback to help children with language impairment improve the efficiency in their communication. The proposed solution maps the sentences commonly used by children into appealing symbols. The children can use these symbols instead of constructing sentences from scratch, as done by most of the previously proposed solutions in the literature. The application was evaluated by SLPs on six children with language impairment. This research presents a design methodology when providing such a solution for touch screen devices for people with language impairment. A set of accessibility guidelines is proposed for AAC computer-based solutions, which can help researchers and practitioners. The obtained results prove that the proposed system improves the children's stimulation to communicate and decreases communication time. Such a solution can assist therapists as a resource to improve their patients' communication.
\end{abstract}

Keywords: Augmentative and Alternative Communication; Language Impairment; Picture-Based Communication; Usability Study; User-Centered Design; Stakeholder Co-Design Approach.

\section{INTRODUCTION}

The World Health Organization (WHO) states that $15 \%$ of the world population has a moderate or severe disability. One of such disabilities is language impairment that hinders them from communicating with others. This impairment usually happens because of cerebral palsy due to brain damage (Okumura et al., 1997). Such damage can sometimes result in a motor disorder that prevents them from using computers with a traditional mouse or keyboard (Betke et al., 2002, Doush \& Jarrah, 2019). Using accessories like helmets, iPads, goggles, mouth controllers, and eye controllers can be a solution (Betke et al., 2002, Al-Qudah et al., 2014, Doush \& AlMeraj, 2019).

Advancement in technology has enabled the development of several computer-based devices and software applications that can be used for communication among persons with language impairment (Ramdoss et al., 2012). Dedicated speech-generating devices are costly, difficult to program or customize, and somewhat rigid in accommodating the needs of users (Shane et al., 2012). Yet, modern technological advances have produced electronic devices such as mobile devices, which are venturing into communicational, educational, and rehabilitation programs involving persons with developmental disabilities, as there is an increasing number of applications marketed for these uses (Kagohara et al., 2013). 
A variety of systems were developed for nonvocal people to enhance their independence and competence in their communication skills (Schirmer, 2009). Estimated data shows that there are 3 to 5 potential AAC users per 1,000 users of the general population (Stančić et al., 2013). In a survey related to mobile AAC applications conducted by Niemeijer et al. (2012), it was noted that the majority of users and families that use the full features of AAC applications reported an improvement not just in the communication skills of the users but also in their independence and general well-being.

The literature shows that several AAC solutions have been developed. For example, Reyes et al. (2014) developed an application for structuring sentences for communication; this application has an interface that includes pictographic figures classified into groups and subgroups. Through audio playback feature, these sentences could be voiced on the mobile device. Basile et al. (2014) developed an application for mobile devices that use Android platform; this application allows the user to communicate using common phrases in different environments through the audio playback feature. Ghatkamble et al. (2014) established an AAC application for the sporting setting.

An AAC application promotes the independence of children with autism spectrum disorders (ASD), increases their engagement, and eases their learning process (Cramer et al., 2011, Vlachou \& Drigas 2017). Ward et al. (2013) evaluated an iPad application for a child with ASD and concluded that the use of the application proved to be successful for the child. King et al. (2013) studied the usage of iPad by children with ASD, noted that $51 \%$ of the time spent was on AAC application in comparison to other academic and game applications, and concluded that the iPad could be used to support children with ASD.

Al-Wakeel et al. (2015) evaluated two AAC applications developed for children with ASD based on using eyetracking measurement and noted that it was challenging to maintain autistic children in a fixed position during the testing process. Therefore, in their study, Al-Wakeel et al. asked the guardians of younger and autistic children to answer a questionnaire. Khan et al. (2013) conducted a usability study for an application for people with autism based on a survey provided to their parents or guardians. Barry et al. (2008) noted that, for autistic people, using a survey, was not practical.

The number of dedicated AAC devices that support Arabic language is limited. Arabic is considered the official language in 25 countries, and it is one of the six official languages of the United Nations. More than 250 million people speak Arabic in their daily life (Doush et al., 2016). Yet, available AAC systems use non-Arabic devices and integrate the Arabic sound by prerecording built-in phrases. Such adaptation is not fully integrated into the devices and hence does not cover the strong features readily available in the devices such as word completion and prediction. These features make such devices costly and sometimes unaffordable for speakers with low potentials, adding to the rapid evolution of technology. McNaughton and Light (2013) noted that mobile devices are affordable and socially acceptable in comparison to older electronic AAC devices. An additional advantage is that mobile devices have resources that are easily accessible for people requiring AAC environment (Light and McNaughton, 2012).

This study followed user-centered design (Cook and Polgar, 2014) and stakeholder codesign (Kildea et al., 2019) in which users and practitioners are involved in the design and evaluation stages. The AAC tablet application that uses pictures and voice is developed to help children with language impairment. The proposed solution maps the sentences commonly used by children into appealing symbols. Children can use these symbols instead of constructing sentences from scratch, as done by most of the previously proposed solutions in the literature. The obtained results prove that the proposed system improves the user's stimulation to communicate and decreases the communication time. Such a solution can assist therapists as a resource to improve their patients' communication. The recommended features and the selected design choices can be used as design guidelines when developing solutions for children with language impairment.

\section{METHODOLOGY}

The latest advances in technology enable the development of a mobile application to help AAC users. Grigis and Lazzari (2013) evaluated the traditional communication boards versus tablet-based application on nonvocal individuals and concluded that users have shown interest in the new form of communication (that is, the AAC 
application). Individuals who use AAC can benefit from mobile devices (especially tablets) that outperform dedicated, first-generation AAC devices (Dolic et al., 2012).

Generally, the AAC users follow the following steps: 1) look into symbols, 2) pick the symbol, 3) develop sentences, and finally 4) present or speak the message (Patel, 2011). The developed AAC application enables users with language impairment to express their daily needs, such as desired meals, feelings, and health issues. Furthermore, users can customize the application to their needs by adding their own words and phrases represented by preferred pictures and audio.

\section{Design guidelines}

Mobile technology can be accessed by three-quarters of the world's population today, and in 2011, users downloaded over 30 billion mobile applications globally (World Bank, 2012). There recently has been an outburst of software applications dedicated to supporting communication for the users of AAC (Dolic et al., 2012; Gosnell et al., 2011; Hershberger, 2011; Higginbotham and Jacobs, 2011). Grigis and Lazzari (2013) concluded that communication of people with severe disabilities can be facilitated using tablet devices with their applications. Given the simplicity of touch screen interaction, these devices have proven to be easy and intuitive to use, even by people who are both cognitively and physically challenged.

McNaughton and Light (2013) stated that, to meet their communication needs, people who require AAC can now use mainstream technologies. Access to AAC over mainstream tools has not only increased the visibility of AAC in the society, but also improved its social acceptance. Almost 30\% of families stated that when choosing any device as an AAC solution, their single-most crucial factor was affordability (Meder, 2012). Also, previous researchers suggest that, for users with developmental disabilities, Apple products such as iPods, iPod Touch, iPads, and related devices are viable technological aids (Kagohara et al., 2013). Therefore, based on the aforementioned factors, and according to the feedback from the SLPs of the rehabilitation centers, we selected iPad as its AAC device.

Babic et al. (2015) presented a process life cycle for the software development of an AAC application where a multidisciplinary team was involved in the process, and a user-centered design technique was used. Silva et al. (2018) adopted a methodology that uses best practices in software engineering in their development process by defining functions through a user-centered design approach, as this design is an iterative design procedure where designers focus on the users and their needs in the development phases. Martin et al. (2018) also followed a humancentered design approach that took into consideration various stakeholders. The development process is essential for the success of AAC, as the interface must fulfill the different needs of users (Lubas et al., 2014). In order to develop the solution, we followed stakeholder codesign approach (Kildea et al., 2019, Abu Doush et al., 2017). The stakeholder codesign was followed in designing the present application where all the stakeholders, the development team, including researchers and engineers, and SLPs from the rehabilitation center were involved in the process. The core elements of this approach are the inclusion of all stakeholders in the development process, the identification of user preference by observation and consultation with therapists, allowing simple user customization, users evaluation, and therapist feedback.

Several meetings were held to identify the main functionalities of the application, followed by developing a prototype, and finally developing the final product. SLPs from the rehabilitation centers were heavily involved in this development process, and their inputs were thoroughly reviewed and incorporated into the design.

The application was codesigned with the SLPs of the rehabilitation center. The stakeholder codesign adopted in the development process was refined with the usability study reflecting the users' behaviors in real life vis-à-vis the application. The usability study is covered in detail in subsequent sections. This study was conducted with actual users to optimize the application's usefulness and acceptance.

The literature has a set of proposed recommendations and guidelines that can be applied when developing the AAC system (Wilkinson and Hennig, 2007; Binger and Kent-Walsh, 2012; Saturno et al., 2015). The proposed solution considers the following guidelines that can be applied to devices with a touch screen: 
- User interface customization: the user can configure the interface items attributes such as size, font, color, and scanning time.

- Vocabulary customization: the user can add or remove symbols or words from the system library.

- Storing phrases: the user can store phrases for future use in the sentences.

- Suggesting symbols: to construct phrases quicker, the system suggests symbols for the user.

- Symbol selection customization: the selection of symbols can be automatically changed to be linear or nonlinear to allow faster user access to the symbol.

- Audio feedback: a synthesized voice is provided to the user for the symbols. This allows users not to keep looking at the computer screen and reduce user fatigue.

- Preferred symbols: to provide a precise suggestion for sentences or symbols, the system learns the user's preferred vocabulary. This can fasten communication by reducing the number of shown symbols.

A focus group with two therapists was formed at an early stage of the research to show the user interface and to discuss with them the features of the proposed solution. In their turn, the therapists showed the interface to their clients in therapy and tested it on them. The following recommendations were provided to improve the proposed solution:

- The symbol size has to be big enough, but at the same time, without introducing a scroll on the screen, as it will make the solution more difficult for users.

- Adding audio for the symbols by using the voice of a person who is familiar to the user (for example, mother or brother). This motivates the user more to use the application.

- Providing the possibility of multilingual customization of the audio. This is helpful for some users who communicate with their family members in Arabic and with their therapist or teachers in English.

- Supporting audio customization by allowing the user to add sound for specific symbols or phrases.

\section{Proposed solution design}

Several English AAC applications for children were thoroughly assessed, which are Grid Player, Proloquo2Go, GoTalkNow, TalkBoard, SentenceMatch, and SmartHub. Based on this assessment, the main specifications and features of the proposed application were identified, and they are the most important phrases that must be easy to access, the categories to be included, and the main vocabulary of each category. Also, other issues related to usability were considered, such as the size of the pictures, the number of items per row, and how these components can be reached using switches or other inputs. According to the identified specifications and the recommendations of the SLPs, the application was designed to include the following:

- A welcome screen (Figure 1) that registers the user's information, after which the user can select the voice to be male or female.

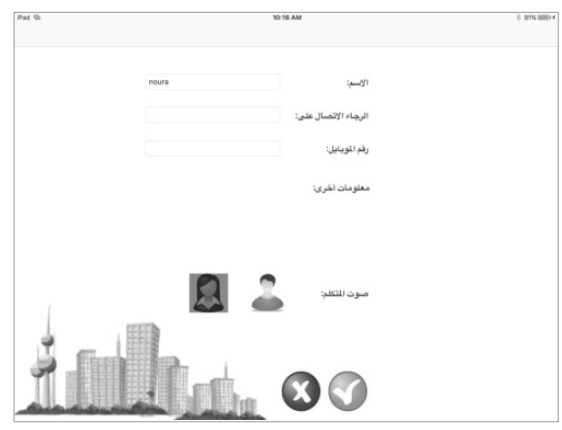

Fig. 1. Welcome screen. 
- Main screen (Figure 2) represents the different categories and the main words or most essential phrases that the user needs. To ensure the simplicity of the design, the number of categories was minimized by grouping pictures within each category.

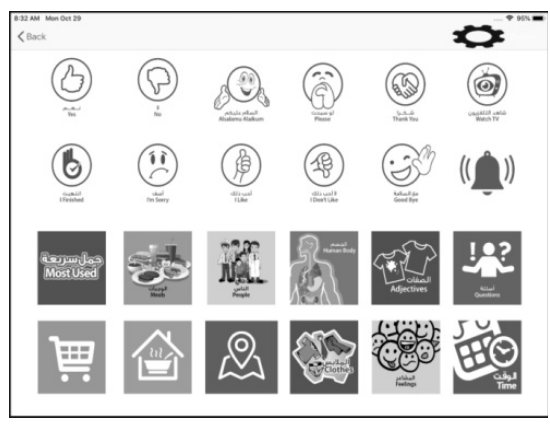

Fig. 2. Main screen.

- Detailed screens that represent each category and display the pictures related to the words or phrases within the selected category. Once the desired picture is selected, the application plays a sound file representing the word or phrase corresponding to that picture. An example of a detailed screen is presented in Figure 3.

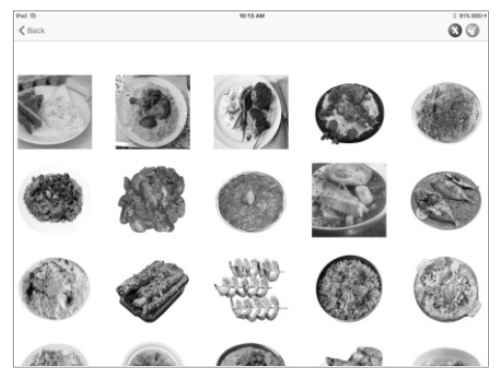

Fig. 3. Selected detailed screen.

The proposed solution uses automatic scanning of the symbols, which utilizes the switch-scan mode of the iPad. Auto scanning is used with auto scanning time of 1.35 seconds with a pause on the first item set to off (that is, the duration of the time auto scanning will wait after the input is pressed). The size used for the symbols in the solution is as follows: (1) size of main page images of the categories is $130 \times 140$, and (2) image size of each detailed page of each category is $210 \times 210$. This variation was made since the categories are limited in number and displayed on the main page, and this allows not having to scroll on the main page.

Several researchers recommed allowing customization and expansion of the vocabulary of AAC applications. Suchato et al. (2011) suggested adding new features using the internet. Caron et al. (2016) argued that the vocabulary in AAC applications is typically preprogrammed by manufacturers, parents, or professionals. When comparing two AAC applications with varying degrees of complexity in adding new vocabulary, it was concluded that the application that required fewer steps had a higher level of interaction with its users.

In addition to the aforementioned specifications, the application includes an additional feature that enables the user to add or delete words or phrases, record sound files, and associate those files with corresponding pictures. This feature proved to be much appreciated by users and SLPs, as discussed in a later section. Figure 4 presents the flowchart that details the customization features. Words or phrases can be added using a simple and guided approach, as the users and their caregivers may have minimal computer skills. 


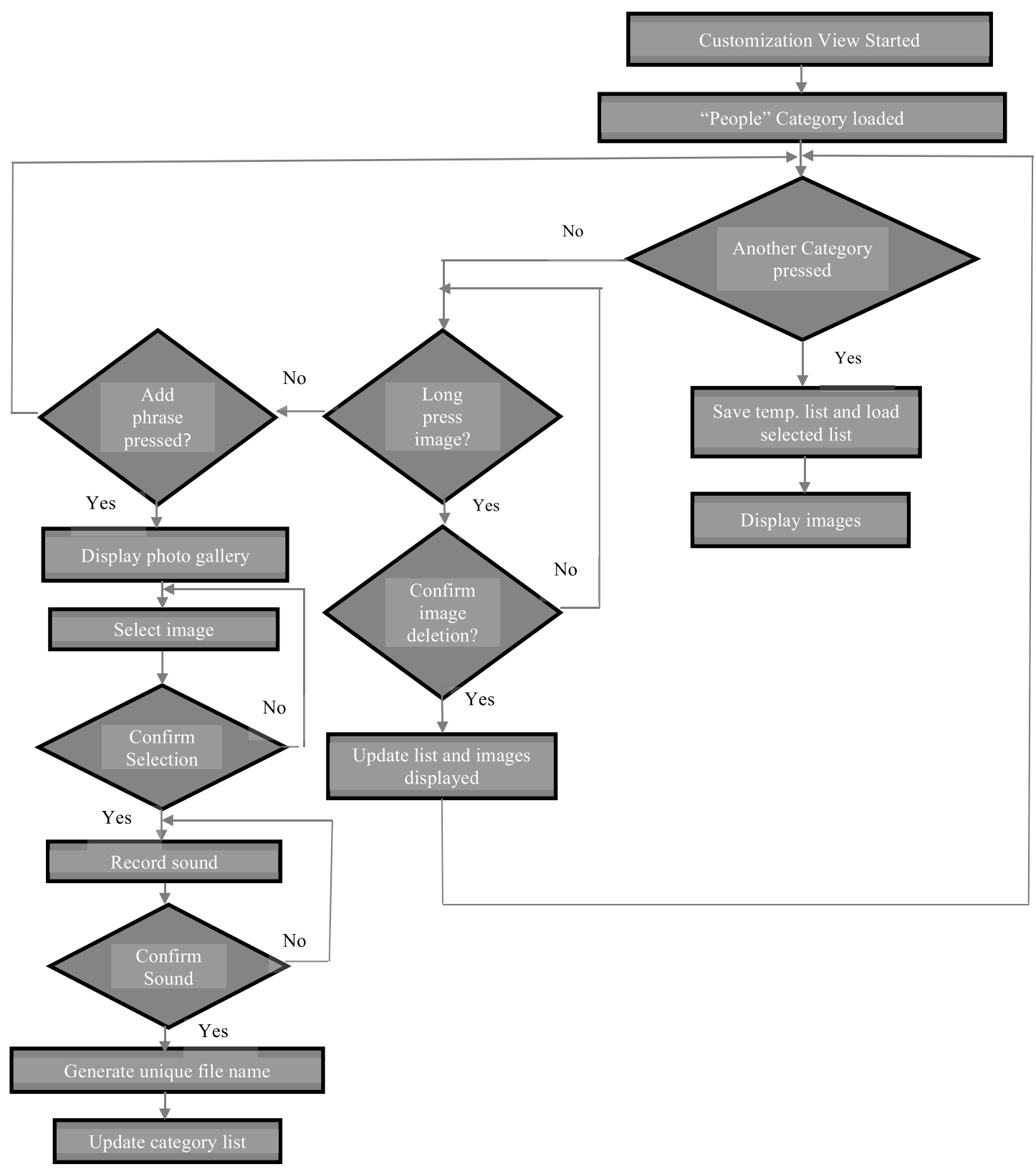

Fig. 4. Flowchart for features customization.

The main objective of an AAC solution is to encourage the integration of individuals with speech difficulties into society (Cook and Polgar, 2014). Ghatkamble et al. (2014), for example, developed a solution with a database covering only the sporting industry. The solution proposed by Silva et al. (2018), on the other hand, offered a database of phrases related to everyday use to widen the interaction of nonvocal individuals with society. The proposed AAC solution was designed to be easy to use and to offer a useful communication tool in order to enhance the independence and the autonomy of users and their integration into the local society.

The main screen of the application displays the most used words or phrases obtained during the focus group meetings, in addition to different categories. The phrases are organized into categories and identified pictographically. 
Twelve categories (Table 1) were selected that included the most used sentences (Table 2), meals, people, human body, adjectives, questions, grocery items, home items, places, clothes, feelings, and time. Each category is composed of several phrases selectively chosen by SLPs. Symbols or pictures were used to represent these phrases. Upon selecting one category, a new page is displayed that contains the pictures of the selected phrases.

Table 1. Categories.

\begin{tabular}{|c|c|c|}
\hline No. & Category & No. of Pictures \\
\hline 1 & Most used sentences & 18 \\
\hline 2 & Meals & 117 \\
\hline 3 & People & 33 \\
\hline 4 & Human body & 42 \\
\hline 5 & Adjectives & 32 \\
\hline 6 & Questions & 12 \\
\hline 7 & Grocery items & 126 \\
\hline 8 & Daily needs & 39 \\
\hline 9 & Places & 30 \\
\hline 10 & Clothes & 41 \\
\hline 11 & Feelings & 13 \\
\hline 12 & Time & 40 \\
\hline
\end{tabular}

Table 2. Categories of most used sentences.

\begin{tabular}{|c|c|c|}
\hline \multicolumn{3}{|c|}{ Most used sentences } \\
\hline Maybe & I read & Good night \\
\hline I want more & You're welcome & How are you? \\
\hline I know & Beautiful day & Alhamdulilah \\
\hline Good morning & Good evening & Goodbye \\
\hline Welcome & I think & I don't mind \\
\hline I want to wash & Thank you & I finished \\
\hline
\end{tabular}

Once the user selects a picture, a sound file is played. The automatic scanning of symbols was set to 1000 milliseconds, and the interval when moving from symbol to another symbol was 100 milliseconds. This was selected to be the default based on the user's need identified during the focus group meetings.

Many researchers have developed solutions for AAC that allow communication through the feature of recorded audio playback (Basile et al., 2014; Mendes and Correia, 2013). The proposed solution includes the option of adding a voice recording. This feature allows the users to build their own list of sentences to communicate based on their daily 
needs. This feature is original and does not exist in many solutions and is highly recommended by the SLPs, as having a familiar person's voice in the solution can stimulate the children to use it. Nonvocal users can include pictures of their family, desired meals, specific clothes, etc. These pictures can be rearranged in the grid, and the user can create his/her photo gallery on his/her personal iPad. With the new picture added to the grid, the narration can also be added by recording the sound file.

The features in the proposed solution can be expanded in a useful way through the camera function that can be used to generate new images. Once created, the images are combined with audio and then integrated into the interface. With the functions developed in the application, the user can add customized phrases. This feature is crucial because more than $70 \%$ of people with communication problems prefer AAC systems that provide predefined messages that can be customized so that the messages can be adapted to users' communication needs (Quintela et al., 2013).

\section{EVALUATION \\ Introduction}

Several existing AAC applications are not based on research evidence. Therefore, these applications might poorly fit the desires and skills of individuals with difficult communication needs. As a result, target users may not attain their anticipated benefits due to the poor design of the AAC application (McNaughton and Light, 2013). Despite the growing number of scientific studies about AAC application development, only a limited number of studies focused on usability (Quintela et al., 2013, Abras et al., 2004).

Turunen et al. (2009) noted that usability evaluation for AAC solutions has not been extensive, and much work still needs to be done. Consequently, target users may not benefit from AAC, not because AAC cannot benefit the users, but rather because the AAC solutions are either difficult or impossible to be used by them (Scardovelli and Frère, 2015, Loja et al., 2015).

Few researchers were reported using usability tests. Silva et al. (2018) used questionnaire for scientific research for mobile devices and used the system usability scale (SUS) questionnaire for the evaluation of their application. Goncalves et al. (2017) evaluated their application using specific tasks assigned to users to assess effectiveness, efficiency, and satisfaction. Babic et al. (2015) identified ten key performance indicators for AAC software development process. These indicators include usefulness for facilitating communication, usefulness for learning, visual attractiveness, acoustical attractiveness, practicality for use in various contexts, being motivating for users, being pleasant to be used, being attractive to be used, ease of use, and applicability for users.

\section{Proposed solution evaluation}

The proposed solution was tested and evaluated by the SLPs of Applied Behavior Center (ABC) in Kuwait based on the input of nonvocal children. Field evaluation of the solution was carried out from September 2018 to January 2019 on six children with language impairment. The SLPs of the behavior center were involved in the evaluation process, as AAC users are nonvocal individuals, and their feedback on usability studies is often conflicting (Babic et al., 2015).

\section{Participants}

Six children with language impairment aged 4-12 participated in the evaluation. At least five users are expected to find $85 \%$ of usability problems (Nielsen, 1993). Table 3 shows the background information of the children, which includes their sex, age, and disability. The kids included one female and five males. Four of the children have autism in addition to language impairment. All of them had experience in using iPad for entertainment. The SLPs at ABC were positive towards trying new technologies to support their work practices. Four of the six children use picture exchange communication system (PECS) or PRoloquo2go applications daily. 
Table 3. Participants' information-ABC.

\begin{tabular}{|l|l|l|l|l|l|l|}
\hline Participant & P1 & P2 & P3 & P4 & P5 & P6 \\
\hline Age & 12 & 6 & 5 & 4 & 4 & 9 \\
\hline Sex & M & F & M & M & M & M \\
\hline Physical Disability & N/A & N/A & N/A & N/A & N/A & N/A \\
\hline Language Delay/Speech Impairment & $\checkmark$ & $\checkmark$ & $\checkmark$ & $\checkmark$ & $\checkmark$ & $\checkmark$ \\
\hline Autism Spectrum Disorder (ASD) & & & $\checkmark$ & $\checkmark$ & $\checkmark$ & $\checkmark$ \\
\hline
\end{tabular}

It is worth noting that all participants were nonvocal, with P1 and P2 having only language delays. Furthermore, P3, P4, P5, and P6 have development delays. P4 and P5 are identical twins, but their skill levels are different.

\section{Procedure}

The children were trained on the application, and afterward, the application usability evaluation was completed with the therapists. The children's feedback was given through their therapists. The children's response when they used the application was in the form of a smile, approaching or pushing away the device, or frustration (if any).

The children were requested to press an icon in the "food" or "most used" category to request for their preferred items (category grid already open from the therapist). Participant 2 and participant 6 were also briefly shown how to navigate in the categories and find the needed folder. None of the participants were taught to add pictures on their own. The therapist described the tasks to them verbally (the therapist says "see (name of child), you can tell me what you need by pressing here") and guided their hand to press the button. As soon as the child pressed an icon, the therapist provided that item. The child got the corresponding food or item for every accurate press on the application so that they could make the connection between pressing an icon and getting the corresponding item.

The children constructed sentences while trying to request for their preferred items. For participants 1, 2, 3, and 4, the training was conducted across two different sessions of 30 minutes each. For participants 5 and 6 , training lasted 15 minutes as they quickly learned to use the solution. SLP could know if the children chose the wrong symbol when they pressed a symbol, and when given the corresponding item, they rejected it.

The therapist was present to assist with adding the pictures of the preferred items to the grids so that the children can request accordingly. After that, the therapist provided physical guidance (hand over or hand support) to guide the child's hand to press the correct picture for a couple of times. Afterward, the therapist allowed the child to use the application on their own.

\section{Usability tests}

Several usability tests were assessed to conduct a usability study. The SUS and user experience Likert scale are used (Brooke, 1996). Interviews and questionnaires were also considered at the start of the study as an initial step. Two sets of questionnaires were used in the usability study: one is for general computer usage, and the other consisted of open-ended questions. These questionnaires aimed to acquire necessary information about the participants, their knowledge, and experiences to determine the perceived usability of the application. The questions used were adapted from Keskinen et al. (2012).

The SLPs interviewed the children and were allowed to translate the terminology and syntax to ensure that the participant understood the question. The SLPs were the primary contacts to the children during the interviews and were instructed to take into account the children's abilities. For example, if the child found a question too abstract or difficult to understand, the SLP presented it in an appropriate way. The questions asked during the evaluation shed light on the experience with the use of the proposed solution. 
A 5-point Likert scale that ranged from 1 (extremely sad) to 5 (extremely happy) was used to evaluate and measure the child's subjective user experience. Table 4 is the output of the user experiences for the six participants.

Table 4. Participants (children)-user Experiences ( 1 = extremely sad-5 = extremely happy).

\begin{tabular}{|c|c|c|c|c|c|c|}
\hline Experience & P1 & P2 & P3 & P4 & P5 & P6 \\
\hline Fast & 4 & 5 & 3 & 3 & 4 & 5 \\
\hline Fun & 4 & 5 & 5 & 5 & 4 & 5 \\
\hline Not Hard & 5 & 5 & 4 & 4 & 5 & 5 \\
\hline Again & 5 & 5 & 5 & 5 & 3 & 5 \\
\hline
\end{tabular}

The SUS is a reputed tool to determine the usability of a system (Brooke, 1996). It is simple and brief and has been found to be robust to conduct numerous studies (Bangor et al., 2008; Bangor et al., 2009; and Bevan, 2009). It consists of a scale ranging from 1, 'strongly disagree,' to 5, 'strongly agree,' and the participants have to answer ten questions using the scale; the result is a score between 0 and 100. The usability of the application is scored as above average if the score is above 68 (Brooke, 2013). It is possible to assess the usability of a software and determine its quality through the results of the SUS questionnaire, where four out of the ten questions were based on learning facility; three questions on efficiency; one question on storage facility; one question on error minimization; and three questions on satisfaction (Tenorio et al., 2011). Table 5 lists the output of the SUS test for the six participants. When the children used the application, there were no signs that showed any form of disappointment or frustration.

Table 5. SUS of participants (children).

\begin{tabular}{|l|c|c|c|c|c|c|}
\hline Participant & P1 & P2 & P3 & P4 & P5 & P6 \\
\hline Overall & 90 & 92.5 & 82.5 & 87.5 & 77.5 & 80 \\
\hline Ease of Learning & 94 & 94 & 69 & 88 & 88 & 81 \\
\hline
\end{tabular}

The subjective assessment of speech system interfaces (SASSI) is a questionnaire consisting of 34 questions (Hone and Graham, 2000). This questionnaire consists of these questions that are classified to assess the following: system response accuracy, likeability, cognitive demand, annoyance, habitability, and speed. Another questionnaire is the poststudy system usability questionnaire (PSSUQ), which consists of 19 items (Lewis, 1991; Wang et al., 2017). These items produce an overall score based on qualities of system, interface, and information. A 7-point Likert scale was used to measure each item. Responses ranged from strongly agree (1) to strongly disagree (7), where a lower score indicates higher perceived usability.

The results of the PSSUQ for the six children, presented in Table 6, were all below 5.5. On a scale from 1 to 7, a low score indicates highly perceived usability. The SASSI gave qualitative indications. As shown in Table 7, most children selected agree or strongly agree on the likeability questions (10-18) and selected disagree or strongly disagree on the annoyance questions (24-28), indicating that the proposed solution is pleasant, friendly, and not boring or irritating.

Table 6. PSSUQ of participants (children).

\begin{tabular}{|c|c|c|c|c|c|c|}
\hline Participant & P1 & P2 & P3 & P4 & P5 & P6 \\
\hline PSSUQ - Overall & 4.8 & 1.2 & 3.0 & 3.2 & 5.5 & 2.3 \\
\hline
\end{tabular}


Table 7. SASSI of participants (children).

\begin{tabular}{|c|c|c|c|c|c|c|}
\hline Participant & P1 & P2 & P3 & P4 & P5 & P6 \\
\hline Q10 & $\begin{array}{l}\text { Slightly } \\
\text { agree }\end{array}$ & $\begin{array}{l}\text { Strongly } \\
\text { agree }\end{array}$ & Strongly agree & $\begin{array}{c}\text { Strongly } \\
\text { agree }\end{array}$ & Agree & Strongly agree \\
\hline Q11 & $\begin{array}{l}\text { Slightly } \\
\text { agree }\end{array}$ & $\begin{array}{l}\text { Strongly } \\
\text { agree }\end{array}$ & Strongly agree & $\begin{array}{c}\text { Strongly } \\
\text { agree }\end{array}$ & Agree & Agree \\
\hline Q12 & $\begin{array}{l}\text { Slightly } \\
\text { agree }\end{array}$ & $\begin{array}{l}\text { Strongly } \\
\text { agree }\end{array}$ & Strongly agree & $\begin{array}{c}\text { Strongly } \\
\text { agree }\end{array}$ & Agree & Strongly agree \\
\hline Q13 & Disagree & Neutral & Agree & $\begin{array}{c}\text { Slightly } \\
\text { agree }\end{array}$ & Agree & Strongly agree \\
\hline Q14 & $\begin{array}{l}\text { Slightly } \\
\text { disagree }\end{array}$ & $\begin{array}{l}\text { Strongly } \\
\text { agree }\end{array}$ & Strongly agree & $\begin{array}{c}\text { Strongly } \\
\text { agree }\end{array}$ & $\begin{array}{l}\text { Slightly } \\
\text { agree }\end{array}$ & Strongly agree \\
\hline Q15 & Neutral & $\begin{array}{l}\text { Strongly } \\
\text { agree }\end{array}$ & $\begin{array}{l}\text { Slightly } \\
\text { disagree }\end{array}$ & Agree & $\begin{array}{l}\text { Strongly } \\
\text { agree }\end{array}$ & Neutral \\
\hline Q16 & Neutral & $\begin{array}{l}\text { Strongly } \\
\text { agree }\end{array}$ & Neutral & Agree & $\begin{array}{l}\text { Strongly } \\
\text { agree }\end{array}$ & Neutral \\
\hline Q17 & Disagree & $\begin{array}{l}\text { Strongly } \\
\text { agree }\end{array}$ & Strongly agree & $\begin{array}{c}\text { Strongly } \\
\text { agree }\end{array}$ & $\begin{array}{l}\text { Slightly } \\
\text { agree }\end{array}$ & Slightly agree \\
\hline Q18 & $\begin{array}{l}\text { Slightly } \\
\text { disagree }\end{array}$ & Slightly agree & Neutral & Agree & Disagree & Slightly agree \\
\hline Q24 & $\begin{array}{l}\text { Slightly } \\
\text { disagree }\end{array}$ & Disagree & Disagree & $\begin{array}{c}\text { Slightly } \\
\text { agree }\end{array}$ & Disagree & Strongly disagree \\
\hline Q25 & $\begin{array}{l}\text { Slightly } \\
\text { disagree }\end{array}$ & Disagree & Disagree & $\begin{array}{l}\text { Strongly } \\
\text { disagree }\end{array}$ & Disagree & Strongly disagree \\
\hline Q26 & $\begin{array}{l}\text { Slightly } \\
\text { disagree }\end{array}$ & Disagree & Disagree & $\begin{array}{l}\text { Strongly } \\
\text { disagree }\end{array}$ & $\begin{array}{l}\text { Slightly } \\
\text { disagree }\end{array}$ & Strongly disagree \\
\hline Q27 & $\begin{array}{l}\text { Slightly } \\
\text { disagree }\end{array}$ & Disagree & $\begin{array}{l}\text { Slightly } \\
\text { disagree }\end{array}$ & $\begin{array}{l}\text { Strongly } \\
\text { disagree }\end{array}$ & Disagree & Strongly disagree \\
\hline Q28 & $\begin{array}{l}\text { Slightly } \\
\text { disagree }\end{array}$ & Slightly agree & Agree & Disagree & Neutral & Agree \\
\hline
\end{tabular}

\section{Qualitative measures}

We generated two word clouds for the children to respond to regarding the features of the proposed solution that were most liked (question 1) and those that needed enhancement (question 2). The results of question 1 (Figure 5) showed that the most favored features of the application were the pictures used in the application, followed by the portability of the application. The results of question 2 (Figure 6) showed that the primarily suggested enhancement was customization with facility for each child to adjust the pictures and the features. 


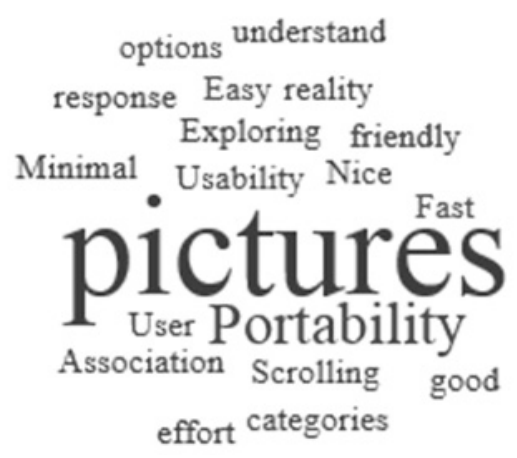

Fig. 5. Word cloud representation of most liked features.

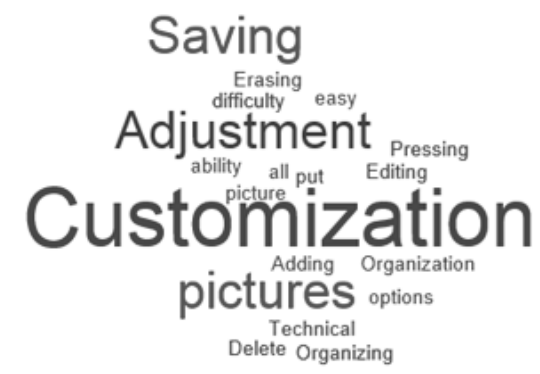

Fig. 6. Word cloud representation of features in need of enhancement.

\section{RESULTS AND DISCUSSIONS}

The proposed solution constructs highly personalized communication for various situations taking into account the user's individual needs, which includes customizing the vocabulary of the communication, pictures, and recorded voice outputs. Based on the feedback of the SLPs at ABC, it was noted that the users liked the option of choosing words and pictures that accommodate the local culture, specifically local dishes such as the ones presented in Figure 3 . The users also liked the features of personalizing the words and pictures to represent their needs and customizing the voice by recording a familiar voice. These observations are in line with those of Babic et al. (2015), who noted that one of the essential characteristics when developing AAC solutions is the adaptation of the content and the user interface to users' needs.

Grigis and Lazzari (2013) also noted that it is of paramount importance to customize the programs and the flexibility of their graphical interface in order to optimize their use for different users and to adapt them to the needs of each person. Images or personal photographs used as alternatives to symbols proved to be an effective way of expressing specific concepts.

The SLPs noted that using the proposed solution would help the children when communicating in family gatherings, notably, communicating with their grandparents. This benefit was attained with the use of pictures reflecting the local culture. The customization of voice recording was also very useful in accommodating the bilingual Kuwaiti society. Participants needed to communicate in Arabic with their family, especially the elderly, and in English with their caregivers.

We could draw interesting conclusions about the proposed system from the results of the usability study. The tests were completed by the SLPs together with the children. The SLPs took into consideration the child's reactions like smiling, frequency of approaching the device, frequency of pressing, the symbol in the solution, frequency of scrolling through the categories, and frequency of selecting the wrong symbol while using the application to ensure objectivity as much as possible. 
The results of the SUS usability tests are listed in Table 5. These results showed a positive evaluation from all the children. The SUS scores were all above 68 , signifying that the usability of the application is considered above average (Brooke, 2013). Children such as P1 and P2 who are familiar with communication systems scored higher on the SUS test. P1 and P2, who only have language impairment, scored higher than P3, P4, P5, and P6, who have additional development delays. P1 and P2 scored 90 and 92.5, respectively; these higher scores were attributed to their previous training and not their age. The oldest in the group is $\mathrm{P} 1$ who is aged 12, and P2 is aged 6.

The scores in Tables 4 and 5 reflect the children's skillsets. P2 is the most advanced in the group. She communicates through the use of PECS, discriminates among PECS pictures, exchanges the picture to get the corresponding item, and requests seven items per day on average, including edibles and toys. P2 used the application properly, navigated between the different categories on her own, and edited the grocery items. P3 and P4 communicated through the use of PECS, but their scores in Tables 4 and 5 are inferior to those of P2. P3 was able to request 5 of his preferred items a day on average, while P4 was able to request 4 of his preferred items on a daily average. Both P3 and P4 used only the "most used" category in which the default pictures are replaced with their preferred items. P3 and P4 did not open any category other than the one that the SLP had opened for them.

Participants P3, P4, P5, and P6 are autistic, and their scores on the SUS test were 82.5, 87.5, 77.5, and 80, respectively. Table 4 shows that P3, P4, P6, and P5, to a lesser extent, liked the application, enjoyed using it, and would like to use it again. Vlachou and Drigas (2017) concluded that mobile technology appeals to autistic children whose communication skills are lacking and who are eager to play with portable devices.

Children P3, P4, P5, and P6 scored lower than P1 and P2 on the SUS test mainly due to questions (3, 4, 7, and 10) related to ease of learning. These children are in the training phase and need training before using AAC communication application. Also, P3 is not trained and needed training on one picture at a time. Therefore, the option of deleting and adding pictures was crucial for P3, who scored lowest on ease of learning in comparison to the other participants, as can be seen in Table 5. As noted by Hayes et al. (2014), unless the user can interact with the application, predetermined applications are not flexible enough to support the activities involved in caring for children with autism.

P6, on the other hand, uses Proloquo2go to communicate his requests in English. He navigates well through the different categories within his AAC application and can request the desired item and reject an offered one. While using the proposed solution, P6 preferred to add an item to the "most used" category. After a brief introduction, P6 was able to navigate through the categories, reject a nondesired item, open the "most used" category, and add the desired item. This indicated that P6 interacted reasonably well with the proposed solution, but he is used to his Proloquo2go application. This preference is reflected in his SUS score.

The results of the word clouds presented in Figures 5 and 6 confirm that the children enjoyed using the application. The most liked features of the proposed solution were the pictures used, followed by the portability of the application on the iPad. The most liked feature confirms the fact that the pictures that reflect the local culture are desirable. The portability of the application is in line with the positive results of different studies suggesting the use of the iPad as a technological aid for users with developmental disabilities. It is also in accordance with the recommendation of the SLPs of the rehabilitation centers during the design stage. The desired enhancement, on the other hand, was related to picture customization for each child. Customization features followed a simple and guided approach, but it was noted that further training is needed on customization involving adding, deleting, and storing files.

With the stakeholder codesign approach, the proposed solution was tailored to the needs of the users while accommodating the recommendations of the SLPs, and the usability study enabled the development team to optimize the application according to the users' needs.

\section{CONCLUSION AND FUTURE WORK}

In this paper, the $\mathrm{AAC}$ solution for tablets and mobile devices was developed to help children with language impairment. The study was conducted in a rehabilitation center in Kuwait City, Kuwait. The proposed solution followed a stakeholder codesign approach. It considers the design guidelines recommended by the literature. Furthermore, the 
feedback from the users and therapists allows the enhancement of the proposed solution by sizing the symbols on the screen in a way that will not result in scrolling, using a familiar voice for the symbol, and providing the possibility of multilingual customization of the audio for the symbols and phrases. The solution provides users with different categories that can help them construct different phrases. The solution allows the user to construct phrases in Arabic or any other language. The twelve categories provided for the user are chosen after receiving the therapist's feedback about the important phrases for daily communication with the children.

The proposed tool increases the users' communication efficiency when compared to other solutions in the literature as it maps commonly used sentences by the children into appealing symbols. Most of the previous researchers proposed AAC solution, which constructs sentences using 2-4 symbols. The solution in the current study relies on offering the symbols that present sentences to children. The effort required by the children to communicate with others is minimized, as the time needed to construct the sentence is reduced. The solution allows the users to customize the user interface by adding or removing symbols or attaching a spoken sound to the symbols. The solution was evaluated with six children with language impairment; four of them are with ASD. The therapist was present when the solution was evaluated. The evaluation results show that children like to use the proposed solution and that it effectively enables them to communicate with people.

The software development methodology applied to provide the solution proves that it is not only important to apply the accessibility guidelines, but also essential to involve therapists in the solution design, especially when developing solutions for people with language impairment.

Such a tool is urgently needed in rehabilitation and behavior centers to enable challenged individuals to communicate with their community. The results of the usability studies were largely positive, suggesting that the developed solution can be a viable technological aid for nonvocal individuals. The need for collaboration between research bodies and rehabilitation centers should be highlighted and followed through in order to support various research and development activities and ensure that advanced technologies enhancing communication for nonvocal individuals and their families are successfully implemented.

The proposed solution can be used as a multilingual tool for communication, and a future study can evaluate if the proposed solution expands the children's vocabulary in two languages, Arabic and English. The categories and sentences can be revised by adding or deleting sentences in each category. The proposed solution can also improve communication for children with autism. In such future study, children's engagement can be assessed based on a survey conducted before and after using the application to see whether the children who use the application are now communicating better or initiate chats with others. Lastly, the proposed solution can be evaluated with more individuals with severe cases of motor impairment and can recommend what customization can be applied to the solution to fit their needs. Although the iPad provides accessibility tools, such as scan mode, switches, and voice over (text-to-speech), the proposed solution can be further studied to check compatibility and recommend design measures. Considering such study, the proposed solution must be modified where recorded narrations are replaced by typed texts.

\section{ETHICS STATEMENT}

A full explanation was provided to SLPs involved in the usability study about the details of the study and the roles of the participants. Also, consent forms were signed by the guardians of the children who participated in the usability study.

\section{ACKNOWLEDGMENT}

The authors gratefully acknowledge the SLPs of the rehabilitation centers for their support in testing and verifying the developed application. It was only because of their support that the team managed to develop the applications catered to the actual needs of individuals with communication impairment. The authors would also like to thank and acknowledge the SLPs at Applied Behavior Center (ABC) in Kuwait for their help and enormous support in conducting the usability study between September 2018 and January 2019. Their patience and perseverance are highly appreciated. 


\section{REFERENCES}

Abras, C., Maloney-Krichmar, D., \& Preece, J. 2004. User-centered design. Bainbridge, W. Encyclopedia of Human-Computer Interaction. Thousand Oaks: Sage Publications, 37(4): 445-456.

Abu Doush, I., Alshatnawi, S., Al-Tamimi, A. K., Alhasan, B., \& Hamasha, S. 2017. ISAB: integrated indoor navigation system for the blind. Interacting with Computers, 29(2): 181-202.

Al-Qudah, Z., Doush, I.A., Alkhateeb, F., Al Maghayreh, E., \& Al-Khaleel, O. 2014. Utilizing mobile devices' tactile feedback for presenting braille characters: an optimized approach for fast reading and long battery life. Interacting with Computers, 26(1): 63-74.

Al-Wakeel, L., Al-Ghanim, A., Al-Zeer, S., \& Al-Nafjan, K. 2015. A usability evaluation of arabic mobile applications designed for children with special needs--Autism. Lecture Notes on Software Engineering, 3(3): 203.

Babic, J., Slivar, I., Car, Z., \& Podobnik, V. 2015. Prototype-driven software development process for augmentative and alternative communication applications. In Telecommunications (ConTEL), 2015 13th International Conference on (pp. 1-8). IEEE.

Bangor, A., Kortum, P.T., \& Miller, J.T. 2008. An empirical evaluation of the system usability scale. International Journal of Human-Computer Interaction, 24(6): 574-594.

Bangor, A., Kortum, P., \& Miller, J. 2009. Determining what individual SUS scores mean: Adding an adjective rating scale. Journal of usability studies, 4(3): 114-123.

Bank, T.W. 2012. Mobile Phone Access Reaches Three Quarters of Planet's Population. World Bank Group Press Release, 15.

Basile, F.R.M., da Silva, D.P., \& Amate, F.C. 2014. Mobile application to aid people with speech disorders. Journal of Health Informatics, 6(2).

Barry, M., Kehoe, A., \& Pitt, I. 2008. Usability Evaluation of Educational Game Software for Children with Autism. In EdMedia: World Conference on Educational Media and Technology (pp. 1366-1370). Association for the Advancement of Computing in Education (AACE).

Betke, M., Gips, J., \& Fleming, P. 2002. The camera mouse: visual tracking of body features to provide computer access for people with severe disabilities. IEEE Transactions on neural systems and Rehabilitation Engineering, 10(1): 1-10.

Bevan, N. 2009. International standards for usability should be more widely used. Journal of Usability Studies, 4(3): 106-113.

Binger, C., \& Kent-Walsh, J. 2012. Selecting skills to teach communication partners: Where do I start? Perspectives on Augmentative and Alternative Communication, 21(4): 127-135.

Brooke, J. 1996. SUS-A quick and dirty usability scale. Usability evaluation in industry, 189(194): 4-7.

Brooke, J. 2013. SUS: a retrospective. Journal of usability studies, 8(2): 29-40.

Caron, J., Light, J., \& Drager, K. 2016. Operational demands of AAC mobile technology applications on programming vocabulary and engagement during professional and child interactions. Augmentative and Alternative Communication, 32(1): 12-24.

Cook, A.M., \& Polgar, J.M. 2014. Assistive Technologies-E-Book: Principles and Practice. Elsevier Health Sciences.

Cramer, M., Hirano, S.H., Tentori, M., Yeganyan, M.T., \& Hayes, G.R. 2011. Classroom-based assistive technology: collective use of interactive visual schedules by students with autism. In CHI (Vol. 11, pp. 1-10).

de los Reyes, J., Rodriguez, A.N., Umali, E.D., Solamo, R., \& Feria, R. 2014. Evaluation of a mobile AAC application for Filipino language. InInformation, Intelligence, Systems and Applications, IISA 2014, The 5th International Conference on (pp. 137-142). IEEE.

Dolic, J., Pibernik, J., \& Bota, J. 2012. Evaluation of mainstream tablet devices for symbol based AAC communication. In KES International Symposium on Agent and Multi-Agent Systems: Technologies and Applications (pp. 251-260). Springer, Berlin, Heidelberg.

Doush, I.A., Alkhatib, F., \& Bsoul, A.A.R. 2016. What we have and what is needed, how to evaluate Arabic Speech Synthesizer? International Journal of Speech Technology, 19(2): 415-432.

Doush, I., \& AIMeraj, Z. 2019. Evaluating the Accessibility of Kuwaiti E-government Websites. Jordanian Journal of Computers and Information Technology (JJCIT), 5(03). 
Doush, I.A.A., \& Jarrah, S. 2019. Accessible Interface for Context Awareness in Mobile Devices for Users with Memory Impairment. International Journal of Biomedical and Clinical Engineering (IJBCE), 8(2): 1-30.

Ghatkamble, R., Son, J., \& Park, D. 2014. A design and implementation of smartphone-based AAC system.Journal of the Korea Institute of Information and Communication Engineering,18(8): 1895-1903.

Goncalves, C., Rocha, T., Reis, A., \& Barroso, J. 2017. AppVox: an application to assist people with speech impairments in their speech therapy sessions. In World Conference on Information Systems and Technologies (pp. 581-591). Springer, Cham.

Gosnell, J., Costello, J., \& Shane, H. 2011. Using a clinical approach to answer "What communication apps should we use?". Perspectives on Augmentative and Alternative Communication, 20(3): 87-96.

Grigis, D., \&Lazzari, M. 2013. Augmentative and alternative communication on tablet to help persons with severe disabilities. In Proceedings of the Biannual Conference of the Italian Chapter of SIGCHI (p. 17).ACM.

Hart, S.G., \& Staveland, L.E. 1988. Development of NASA-TLX (Task Load Index): Results of empirical and theoretical research. In Advances in psychology (Vol. 52, pp. 139-183). North-Holland.

Hayes, G.R., Kientz, J.A., Truong, K.N., White, D.R., Abowd, G.D., \& Pering, T. 2004. Designing capture applications to support the education of children with autism. In International Conference on Ubiquitous Computing (pp. 161-178). Springer, Berlin, Heidelberg.

Hershberger, D. 2011. Mobile technology and AAC Apps from an AAC developer's perspective. Perspectives on Augmentative and Alternative Communication, 20(1): 28-33.

Higginbotham, J., \& Jacobs, S. 2011. The future of the android operating system for augmentative and alternative communication. SIG 12 Perspectives on Augmentative and Alternative Communication, 20(2): 52-56.

Hone, K.S., \& Graham, R. 2000. Towards a tool for the subjective assessment of speech system interfaces (SASSI). Natural Language Engineering, 6(3-4): 287-303.

Hornof, A.J. 2009. Designing with children with severe motor impairments.In Proceedings of the SIGCHI Conference on Human Factors in Computing Systems (pp. 2177-2180).ACM.

Kagohara, D.M., van der Meer, L., Ramdoss, S., O’Reilly, M.F., Lancioni, G.E., Davis, T.N., ...\& Green, V.A. 2013. Using iPods ${ }^{\circledR}$ and $i \operatorname{Pads} \AA$ in teaching programs for individuals with developmental disabilities: A systematic review. Research in developmental disabilities, 34(1): 147-156.

Keskinen, T., Heimonen, T., Turunen, M., Rajaniemi, J.P., \& Kauppinen, S. 2012. SymbolChat: A flexible picture-based communication platform for users with intellectual disabilities. Interacting with Computers, 24(5): 374-386.

Khan, S., Tahir, M.N., \& Raza, A. 2013. Usability issues for smartphone users with special needs-Autism. In Proc. Int. Conf. on Open Source Systems and Technologies (pp. 107-113).

Kildea, J., Battista, J., Cabral, B., Hendren, L., Herrera, D., Hijal, T., \& Joseph, A. 2019. Design and development of a personcentered patient portal using participatory stakeholder co-design. Journal of medical Internet research, 21(2): e11371.

King, A.M., Thomeczek, M., Voreis, G., \& Scott, V. 2014. iPad® use in children and young adults with Autism Spectrum Disorder: An observational study. Child Language Teaching and Therapy, 30(2): 159-173.

Lewis, J.R. 1991. User satisfaction questionnaires for usability studies: 1991 manual of directions for the ASQ and PSSUQ (No. 54.609). Boca Raton. FL: Tech. Rep.

Light, J., \& McNaughton, D. 2012. The changing face of augmentative and alternative communication: Past, present, and future challenges.

Loja, L.F.B., Gomide, R.D.S., Mendes, F.F., Teixeira, R.A.G., Lemos, R.P., \& Flôres, E.L. 2015. A concept-environment for computer-based augmentative and alternative communication founded on a systematic review. Research on Biomedical Engineering, (AHEAD), 0-0.

Lubas, M., Mitchell, J., \& De Leo, G. 2014. User-centered design and augmentative and alternative communication apps for children with autism spectrum disorders. Sage Open, 4(2): 2158244014537501.

McNaughton, D., \& Light, J. 2013. The iPad and mobile technology revolution: Benefits and challenges for individuals who require augmentative and alternative communication. 
Martin, E., Cupeiro, C., Pizarro, L., Roldán-Álvarez, D., \& Montero-de-Espinosa, G. 2019. "Today I Tell” A Comics and Story Creation App for People with Autism Spectrum Condition. International Journal of Human-Computer Interaction, 35(8): 679-691.

Meder, A. 2012. Mobile media devices and communication applications as a form of augmentative and alternative communication: An assessment of family wants, needs, and preferences (Doctoral dissertation, University of Kansas).

Mendes, M., \& Correia, S. 2013. Combining research, theory and end user experiments for suitable AAC apps.Assistive Technology: From Research to Practice: AAATE 2013,33, 340.

Niemeijer, D., Donnellan, A., \& Robledo, J. 2012. Taking the pulse of augmentative and alternative communication on iOS. Retrieved from the Assistive Ware website: http://www.assistiveware.com/taking-pulse-augmentative-andalternativecommunication-ios.

Nielsen, J. 1993. Usability Engineering. San Francisco: Morgan Kaufmann.

Okumura, A., Kato, T., Kuno, K., Hayakawa, F., \& Watanabe, K. 1997. MRI findings in patients with spastic cerebral palsy. II: Correlation with type of cerebral palsy. Developmental medicine and child neurology, 39(6): 369-372.

Patel, R. 2011. Message formulation, organization, and navigation schemes for icon-based communication aids. In 2011 Annual International Conference of the IEEE Engineering in Medicine and Biology Society (pp. 5364-5367). IEEE.

Quintela, M.A., Correia, S., \& Mendes, M. 2013. Augmentative and alternative communication: Vox4all ${ }^{\circledR}$ presentation. In 2013 8th Iberian Conference on Information Systems and Technologies (CISTI) (pp. 1-6). IEEE.

Ramdoss, S., Lang, R., Fragale, C., Britt, C., O’Reilly, M., Sigafoos, J., ...\& Lancioni, G.E. 2012. Use of computer-based interventions to promote daily living skills in individuals with intellectual disabilities: A systematic review. Journal of Developmental and Physical Disabilities, 24(2): 197-215.

Riegler, A., \& Holzmann, C. 2018. Measuring Visual User Interface Complexity of Mobile Applications with Metrics. Interacting with Computers, 30(3): 207-223.

Rocha, T., Silva, P., Barreira, M., \& Barroso, J. 2018. DIGA OLÁ: An Augmentative and Alternative Communication (AAC) Mobile Application for People with Language and Speech Impairments. In International Conference on Computers Helping People with Special Needs (pp. 533-538). Springer, Cham.

Saturno, C.E., Ramirez, A.R.G., Conte, M.J., Farhat, M., \& Piucco, E.C. 2015. An augmentative and alternative communication tool for children and adolescents with cerebral palsy. Behaviour \& Information Technology, 34(6): 632-645.

Scardovelli, T.A., \& Frère, A.F. 2015. The design and evaluation of a peripheral device for use with a computer game intended for children with motor disabilities.Computer methods and programs in biomedicine, 118(1): 44-58.

Schirmer, C.R. 2009. Acessibilidade na comunicação é um direito-comunicação alternativa é um caminho. RevistaTeias, 9(18): 9-pgs.

Shane, H.C., Blackstone, S., Vanderheiden, G., Williams, M., \& DeRuyter, F. 2012. Using AAC technology to access the world. Assistive technology, 24(1): 3-13.

Silva, D.P.D., Amate, F.C., Basile, F.R.M., Bianchi Filho, C., Rodrigues, S.C.M., \& Bissaco, M.A.S. 2018. AACVOX: mobile application for augmentative alternative communication to help people with speech disorder and motor impairment. Research on Biomedical Engineering, 34(2): 166-175.

Stančić, Z., Škrinjar, J.F., Ljubešić, M., \& Car, Ž. 2011. Multidisciplinary collaboration and ICT services for people with complex communication needs. In MIPRO, 2011 Proceedings of the 34th International Convention (pp. 236-241). IEEE.

Suchato, A., Chetsiri, V., Skulareemit, V., Thongprasert, P., \& Punyabukkana, P. 2011. Multilingual AAC on android. In Proceedings of the 5th International Conference on Rehabilitation Engineering \& Assistive Technology (p. 5). Singapore Therapeutic, Assistive \& Rehabilitative Technologies (START) Centre.

Tenorio, J.M., Hummel, A.D., Cohrs, F.M., Sdepanian, V.L., Pisa, I.T., \& de Fátima Marin, H. 2011. Artificial intelligence techniques applied to the development of a decision-support system for diagnosing celiac disease. International journal of medical informatics, 80(11): 793-802.

Turunen, M., Hakulinen, J., Melto, A., Heimonen, T., Laivo, T., \& Hella, J. 2009. SUXES-user experience evaluation method for spoken and multimodal interaction. In Tenth Annual Conference of the International Speech Communication Association. 
Vlachou, J., \& Drigas, A. 2017. Mobile Technology for Students \& Adults with Autistic Spectrum Disorders (ASD). International Journal of Interactive Mobile Technologies (iJIM), 11(1): 4-17.

Wang, E.H., Zhou, L., Chen, S.H.K., Hill, K., \& Parmanto, B. 2017. Development and evaluation of a mobile AAC: a virtual therapist and speech assistant for people with communication disabilities. Disability and Rehabilitation: Assistive Technology, 1-9.

Ward, M., McLaughlin, T.F., Neyman, J., \& Clark, A. 2013. Use of an iPad application as functional communication for a fiveyear-old preschool student with autism spectrum disorder. International Journal of English and Education, 4: 231-238.

Wilkinson, K.M., \& Hennig, S. 2007. The state of research and practice in augmentative and alternative communication for children with developmental/intellectual disabilities. Mental retardation and developmental disabilities research reviews, 13(1): 58-69.

World Health Organization, WHO. 2011. World report on disability [Internet]. Geneva. https://www.ncbi.nlm.nih.gov/books/ NBK304079/. 